\title{
Safety Management Practices and Occupational Health and Safety Performance: An Empirical Review
}

\author{
Muhammad Ajmal*1, Ahmad Shahrul Nizam Isha ${ }^{2} \&$ Shahrina Md Nordin $^{3}$ \\ 1,2,3 Universiti Teknologi PETRONAS, Perak, Malaysia
}

\begin{abstract}
This paper aims to investigate how the relationship between safety management practices and occupational health and safety performance have been examined in the literature, and which future research areas can be recommended. This systematic literature review applied the matrix method to examine major literature in safety management practices and occupational health and safety performance. A total of 24 papers in English peer-reviewed from 21 journals were selected and analyzed. The synthesis of these empirical studies revealed the following: The relationship between safety management practices and occupational health and safety performance has mostly been investigated quantitatively in many countries and sectors; management commitment to safety, safety rules, and procedures and safety training are still most commonly used safety management practices to improve occupational health and safety performance. In this study, research articles were selected only from English journals; therefore, some research articles in other languages might not be included. The findings of this study can be used to develop a safety management model to reduce the rate of injuries, accidents, and near misses in high hazardous risk organizations. Overall, the findings provide Safety management practices overview that practitioners use to manage safety performance. There are only a few systematic literature reviews available on safety management practices, occupational health, and safety performance. This paper is among the first systematic literature reviews to analyze how safety management practices have been associated with occupational health and safety performance and provide potential research avenues.
\end{abstract}

Key words: Safety knowledge, Safety motivation, Safety management, Near misses, Injuries, Accidents

\section{Introduction}

Safety management practices enable organizations to reduce the chances of accidents, injuries, and near misses (Vinodkumar and Bhasi, 2010). According to Kirwan (1998), safety management practices are the actual roles in the organization to remain safe. Therefore, it is quite understandable that to ensure occupational health and safety remains the biggest challenge for practitioners and theorists alike (Clarke, 2006; Fruhen et al., 2019; Lestari et al., 2019; Zohar, 2010). According to the International Labor Organization (ILO - 2018) workers around

*Corresponding author.

Email: m.ajmal303@gmail.com 
the world continue to bear millions of injuries and deaths. However, there are various safety management practices that are used to enhance occupational health and safety performance (Hanafi et al., 2018) and to reduce the rate of accidents and injuries at the workplace (Lee, 2018). The poor conceptualization for safety management practices and interchangeable terms compel for development of a holistic framework that encompasses different aspects of safety management practices (Autenrieth et al., 2016). Besides, in previous research studies, scholars have identified the role of safety management practices to enhance occupational health and safety performance (Almost et al., 2019; Baldassarre et al., 2020; Hanafi et al., 2018; Lee, 2018; Liu et al., 2020; Vinodkumar and Bhasi, 2010; Zimolong and Elke, 2006). However, the rate of accidents, injuries, and health and safety expenses revealed the fundamental concerns for the study designs and safety management models (Alingh et al., 2018; Amponsah-Tawaih and Adu, 2016; Aziz, 1993). Added to this, occupational health and safety-related theories have evolved dramatically and resulted in various safety management practices in the last decade (Zohar, 2000). To date, no successful attempts have been made to create a unified framework for safety management practices and occupational health and safety performance. For example Hanafi et al. (2018); Lee (2018); Vinodkumar and Bhasi (2010); Vredenburgh (2002) conducted a literature review to synthesize literature on safety management practices and occupational health and safety performance. In hazardous organizations, e.g. oil and gas, construction, management needs to adopt a safety management model to reduce the chances of accidents (Amponsah-Tawaih and Adu, 2016). However, the scope of studies (Hanafi et al., 2018; Lee, 2018; Liu et al., 2020; Vinodkumar and Bhasi, 2010; Vredenburgh, 2002) was limited to only safety management practices at the strategic level of the organization. To address these gaps within the literature of safety management practices and occupational health and safety performance, we believe that there is a need to update the systematic literature review.

This systematic review is important because it synthesizes existing body of knowledge and adds structure to the scattered literature on safety management practices and occupational health and safety performance. This paper also makes an important methodological contribution to synthesize the literature from the oil and gas industry where concepts were poorly conceptualized for safety management practices and occupational health and safety performance. This study is also helpful for the management to develop a safety management model to reduce the rate of accidents and injuries, which indirectly contribute to improving occupational health and safety performance.

\section{Theoretical Background}

\subsection{Safety Management Practices}

According to Ladewski and Al-Bayati (2019), safety management practices are the functions that are used to manage organizational occupational health and safety performance. However, safety management has gained more attention to reduce the rate of accidents and injuries (Haslinda et al., 2016). According to Dyjack et al. (1998), after 1991, safety management has entered in the third phase. Safety management was introduced in the United States of America (USA), and Henrich is the early adopter to audit the safety protocols at the workplace to inspect the safety rules and procedures (Gilkey et al., 2003). According to Vinodkumar and Bhasi (2010) numerous attempts were made to predict safety management practices. Still, only those practices should include in which employees and employers commonly perceived a safe environment (Hanafi et al., 2018). However, previous studies show that organizations with low 
accident rates and injury ratio were characterized by employees safety training, management safety commitment, and display of safety rules and procedures (Dov, 2008; Hanafi et al., 2018; Lee, 2018; Vinodkumar and Bhasi, 2010). Lee (2018) highlighted safety training, workers involvement, and management commitment for safety. According to Hale and Borys (2013); Ros and Gustafson (2015) safety rules and feedback are part of safety management to respond to management commitment for safety in the organization. In safety climate investigation Dov (2008) found that management safety commitment plays an important role to maintain organizational safety performance. Fruhen et al. (2019) argued that employees safety behavior must demonstrate to follow safety rules and procedures. Hence, management safety commitment should be an observable activity to maintain safety performance (Almost et al., 2019; Lee, 2018; Vinodkumar and Bhasi, 2010). In the organization, employees need to be active to participate in occupational health and safety training programs (Mazzetti et al., 2020). In addition, safety training improves employees' knowledge and capabilities to identify risk hazards at the workplace (Mazzetti et al., 2020; Teoh et al., 2020). In addition, safety training also helps to minimize accident risk chances and take corrective measures to prevent workplace accidents (Fruhen et al., 2019; Vinodkumar and Bhasi, 2010). The previous studies show that organizations with a low rate of accidents and injuries were found with good safety training programs (Hanafi et al., 2018; Hofmann and Morgeson, 1999; Zimolong and Elke, 2006). According to Vinodkumar and Bhasi (2010) organizations need to conduct systematic safety training programs to improve the health and safety level of employees. Therefore, safety training is considered an important aspect of safety management for newly recruited employees including orientation sessions, buddy practice, emergency action training practice to improve occupational health and safety performance (Kirwan, 1998; Mearns et al., 2003). Regular communication between supervisors and the workforce is effective management practice to improve workplace health and safety performance (Eklof and Ahlborg Jr, 2016; Heaven et al., 2006; Kim and Scott, 2019; Kim and De Dear, 2013). However, in prior studies surveys among various categories of employees show that communication levels among management, supervisors, and coworkers influence safety performance (Chandrasekar, 2011; Mukherji and Arora, 2017; O'Conaill and Frohlich, 1995). Well documented safety rules and procedures and enforcement from supervisors and managers communicate what action employees can take and what actions they cant take to maintain workplace safety (Reason et al., 1998).

Hence, organizations prioritizing to update safety rules and procedures shows the expression to reduce accidents and injury chances (Hale and Borys, 2013). Further, safety rules and procedures are correlated with rate of accidents and injuries based on the previous findings (?). Nevertheless, in total quality management models, rewards and incentive practices are acceptable to motivate workers work safely in the organization (Ajmal et al., 2020).

International Standards Organization (ISO) 19001-18001 safety management system works around the world (http://www.iso.ch) as a non-profit organization to improve work practices and standards (Vinodkumar and Bhasi, 2010). It has been demonstrated that companies registered with OHSAS 18001 certification perform better in terms of safety performance (Ajmal et al., 2021). Well-documented safety rules and procedures and their enforcement can improve the safety performance and safety behavior of employees (Glendon and Litherland, 2001). The safety rules and procedures may minimize the causes of accidents and injuries because they give a clear picture of safety improvement practices (Reason et al., 1998). However, employees need authority and empowerment to make decisions that affect the safety performance of individual and group-based decisions (Almost et al., 2019; Hanafi et al., 2018; Liu et al., 2020). In safety management employees involvement in decision making has been reported as nega- 
tive, particularly in identifying safety problems ( $\mathrm{O}^{\prime}$ Conaill and Frohlich, 1995). Management safety commitment provides ultimate support to employees and encouragement to follow the safety rules and procedures (Fruhen et al., 2019). Besides, support from the top management reshapes employees' perception and behavior related to safety performance (Borowski et al., 2020; Feng et al., 2011; Hu et al., 2020). Hence, top management is committed in safety training for employees and job design (Zohar, 2010). In the view of literature, many studies have been conducted on management safety commitment including construction, hospitality and heavy vehicle transport (Almost et al., 2019; Alphs and Anand, 1999; Amponsah-Tawaih and Adu, 2016). According to Fruhen et al. (2019); Gilkey et al. (2003) management safety commitment is an important factor that determines the safety outcome for injuries, fatalities and near misses. Further, organizations need to be aware of the importance of safety management commitment to improve safety performance (Autenrieth et al., 2016). However, employees safety behavior contributes to maintain workplace safety performance and develop safety relationships with coworkers at the workplace (DeVaul, 2013). The previous research studies (Gilkey et al., 2003) found that employees behavior with coworkers helps to report risk hazards and problems that can be the cause of any accidents at the workplace (Apisarnthanarak et al., 2014; Asibey et al., 2019; Autenrieth et al., 2016; Fruhen et al., 2019). Similarly, a safety promotion policy is also part of safety management, including rewards and incentives to report safety hazards and unsafe conditions (Dyjack et al., 1998). These compensation practices also create competition among employees to report unsafe actions of coworkers and safety-related problems (Vinodkumar and Bhasi, 2010). In safety management practices, one of the important factors that have been ignored is the usage of drugs at the workplace (Vinodkumar and Bhasi, 2010). However, drug usage control is not included in management safety practice, but it can be included in the survey instrument (Vinodkumar and Bhasi, 2010). Hence, the way seniors and management communicate with their subordinates, influence their safety behavior, whether to participate or not in the safety process at the workplace. The language used to convey a message often determines whether, the safety process is rejected or accepted (Eklof and Ahlborg Jr, 2016). Nevertheless, safety practices depend on communication practices used in an organization (Gao et al., 2019). A safe work environment provides a sense of commitment and lowers the risk of hazards and injuries (Kim and Scott, 2019). In addition, Management provides an open system and two-way communication information related to risks and hazards to work safely (Kim and De Dear, 2013). Employees contribute effectively and consult which encourages to report hazards, near misses, and injuries (Chandrasekar, 2011). Moreover, in decision making involvement of employees is motivated to work safely (Acar and Acar, 2014; Fruhen et al., 2019; Mukherji and Arora, 2017). According to Vinodkumar and Bhasi (2010) behavioral-oriented technique is used for employees involvement in the decision-making process through upward communication within-group or within the organization. Hence, the level of participation ranges from full participation to no participation. Numerous researchers have noted that communication patterns influence safetyrelated issues in the organization (Classen et al., 2020). According to Hoffman (1998) people in high uncertainty avoidance societies tend to want to avoid uncertainty and unpredictability. As a result, work environments in such countries try to provide stability and certainty through clear rules and instructions. Communication barriers present a challenge to adopt safety-related communication in the organization (Mehdibeigi et al., 2018). According to Kim and Scott (2019) effective communication may help to reduce hazards risk. The organizations open-door policy for communication facilitates discussion of threats and challenges at the workplace (Arteta and Giachetti, 2004; Whittaker et al., 1994).

Safety commitment has described the involvement of the individual in safety activities to 
achieve organizational safety goals and improve safety performance at the workplace (Grill et al., 2017; Newnam and Goode, 2019). In the past, many studies have discussed the importance of safety commitment and safety performance (Ajmal et al., 2020). These past studies are showing the importance of safety management practices to manage occupational health and safety performance.

\subsection{Occupational Health and Safety Performance}

The concept of safety performance focuses on maintaining workplace safety through different interventions (Christian et al., 2009). These interventions are mainly considered safety behavior with coworkers while performing a job task (Huang et al., 2016). According to Townsend and Gebhardt (2006), positive behavior of employee's engagement supports to share safety knowledge with coworkers. Furthermore, the performance of workplace safety is measured to minimize accidents and occupational injuries (?). A number of studies addressed that researchers need to point out the factors that lead to serious injuries and accidents and near misses in an organization (Zohar, 2010). However, employees' behavior matters a lot to maintain and enhance safety performance (Hoffman, 1998). According to Miller (2017), safety performance is also associated with an employee's safety compliance and safety commitment in the workplace. While safety behavior indirectly supports the development of a safety culture and enhances safety performance (Grill et al., 2017). Additionally, Neal et al. (2000) argued that safety performance depends on employees' good job performance and safety commitment behavior (Ajmal et al., 2020). In the last decade, numerous studies focus on investigating safety performance predictors. For instance, Bhatnagar (2007); Farndale and Murrer (2015); Ferreira and de Oliveira (2014) found that coworkers' relationships, knowledge of safety, safety commitment level, and leadership are the predictors of safety performance. Safety improvement is a continuous process which improves when organizations take serious initiatives (Pruden and Wadhwa, 2021). However, these initiatives are included in safety training and its implications of learned skills and knowledge (Griffin and $\mathrm{Hu}, 2013)$. In the most hazardous workplace, employees face health and safety issues (Neal et al., 2000). However, these types of problems increase the employees medical expenses for health (Classen et al., 2020; Feng et al., 2011; Hu et al., 2020). According to Pinion et al. (2017) safety performance influences employees' retention rate at the organization. Safety performance in an organization depends on employees safety commitment level and engagement with coworkers (Harris et al., 2014). In previous studies related to safety performance and employees' relationships, Ellinger et al. (2014) argued that when employees engage, they share safety information with coworkers. Employees learn through formal safety trainings (Christian et al., 2009). Workers share information at the workplace when they engage to follow the safety rules and procedures (Viitanen and Siljander, 2021). Safety commitment behaviour is the main concern for safety performance (Potdar et al., 2018). According to Ghosh et al. (2014) employees positive safety commitment behaviour encourages coworkers to implement safety measures and follow the rules. Therefore, organizational safety performance is indirectly the result of employees' job performance (Cousins et al., 2019; Feng et al., 2011). Previous studies of Onubi et al. (2019); Vecchio-Sadus (2007) suggest that organizations need to improve measurement of safety performance process because despite ample training for safety yet the employees face accidents and injury problems (Mazzetti et al., 2020). Numerous past studies have addressed that human error and employees' unsafe acts play an important role to increase the number of accidents and injuries rate (Hu et al., 2020; Huang et al., 2016). 


\subsection{Safety Management Practices and Occupational Health and Safety Per- formance}

Safety management practices have played an important role to improve occupational health and safety performance to reduce the rate of injuries and accidents (Autenrieth et al., 2016). In past researches, several studies have been conducted to understand the correlation between safety management practices and occupational health and safety performance (Ajmal et al., 2020). Earlier scholars emphasized selected safety management practices and didnt include a few more practices to develop a holistic safety management model (Hanafi et al., 2018; Kirwan, 1998; Swuste et al., 2020). In addition, safety management practices and occupational health and safety performance are closely related to maintain safety performance (Fruhen et al., 2019). In recent studies, safety management practices revealed that each practice individually plays an important role to reduce the rate of accidents and injuries (Vinodkumar and Bhasi, 2010). There are implicit assumptions about the relationship between safety management practices and occupational health and safety performance.

In past studies, researchers have used selected variables to develop a framework to investigate the impact of safety management practices on occupational health and safety performance. It is important to systematically study the safety management practices, occupational health and safety performance to understand the relationship between both factors.

\section{Methodology}

In this study, we applied the most reproducible, scientific, and holistic review method that is used in the research for systematic literature review (Inkinen, 2016) and this method is widely accepted in the research field (Thomé et al., 2016). This research study aimed to synthesize the literature related to safety management practices and occupational health and safety performance. In research, the systematic literature review was conducted in the medical field, but later on, it has been adopted in social sciences, management sciences, and relevant fields (Frangieh and Yaacoub, 2017). This method is more rigorous because it helps to exclude irrelevant content and is more effective as compared to the traditional systematic literature review method (Thomé et al., 2016).

\subsection{Search Strategy}

Published papers on safety management practices and occupational health and safety performance were identified through exhaustive searches over web of science, Google scholars, ScienceDirect, and ProQuest Database. The researcher used search string techniques to find relevant published papers from the targeted databases. These techniques included Safety Management Practices, Management of Safety, Safety Management Practices and Occupational Health and Safety Performance, Safety and Management to find study-related papers. Afterward, inclusion standards were developed to include papers in analysis qualitative, quantitative, and mixed method approaches on safety management practices and occupational health and safety performance (OHSP). In the preliminary stage, 65 relevant papers abstracts were selected for inclusion, and later on, it was reduced to 41 papers. The remaining studies were read, and 41 papers were excluded because they were not relevant to safety management practices and occupational health and safety performance. For example, the study by Mearns et al. (2003) focused on the offshore environment and overall safety performance. Besides, 41 papers were excluded, 
including 19 review papers and 13 research papers and 10 were case studies. These excluded papers were out of examining safety management practices and occupational health and safety performance. For example, studies by ? were conducted on safety management practices and occupational health and safety performance, and these studies are relevant to conduct a systematic literature review for safety management practices. All paper filtering processes were carried out carefully, and 24 relevant papers were selected to include in this study. For cross-check, the references list was also reviewed to find additional articles for further analysis of the study.

\subsection{Analysis of the Retrieved Articles}

The matrix of the literature review was developed to organize the information of 24 relevant papers from the past studies. In the systematic literature review, relevant information regarding safety management practices and occupational health and safety performance was extracted. The guidelines of the literature review matrix (Lubbe et al., 2007) were used, including the name of authors; region and industry, research methods, and findings are mentioned in Table.1.

\section{Findings}

This study seeks to provide a comprehensive systematic literature review and examined how safety management practices play an important role in occupational health and safety performance. The synthesis of empirical studies that have been conducted previously revealed the following findings.

\subsection{Distribution of Publications}

The publications on safety management practices and occupational health and safety performance have been shown in (Figure.1). In an earlier paper on safety management practices and occupational health and safety performance was from Vredenburgh (2002) on the USA health sector. 


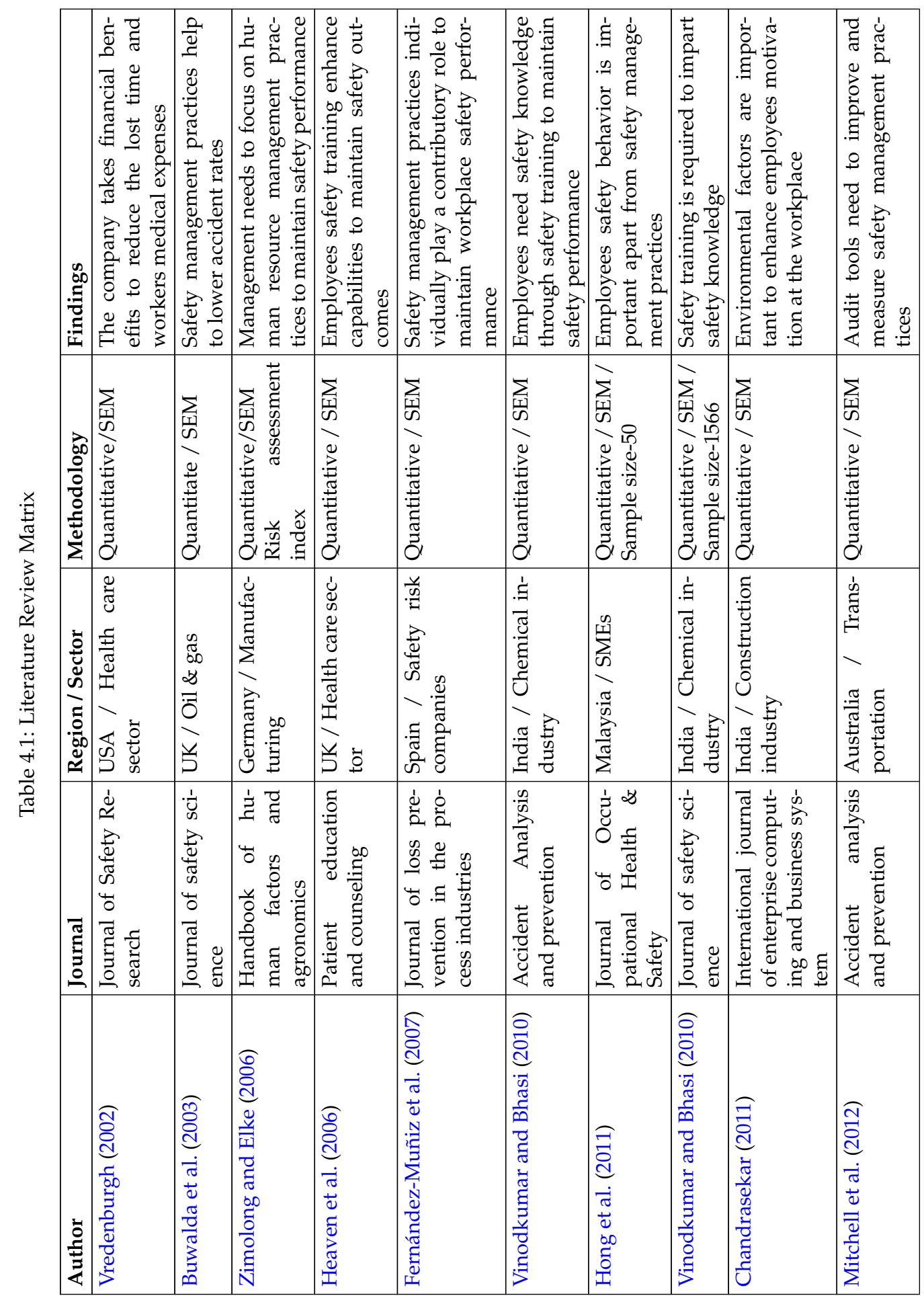




\begin{tabular}{|c|c|c|c|c|c|c|c|c|c|c|}
\hline$\infty$ & 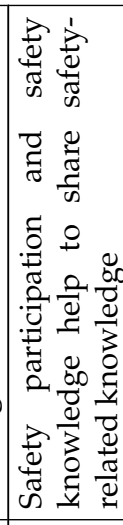 & 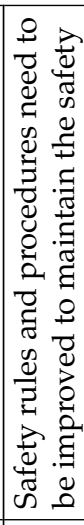 & 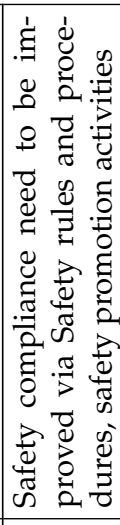 & 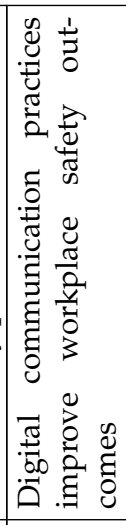 & 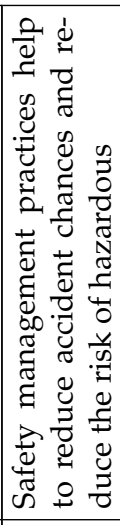 & 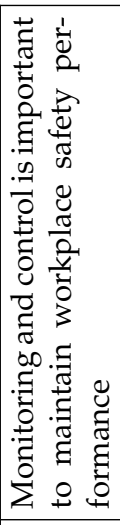 & 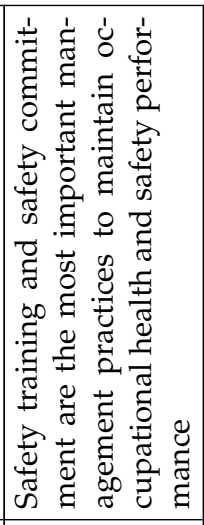 & 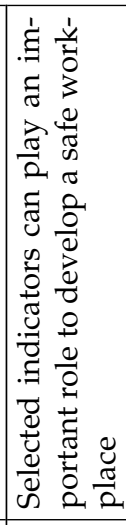 & 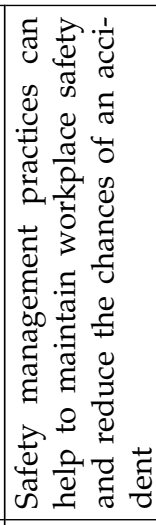 & 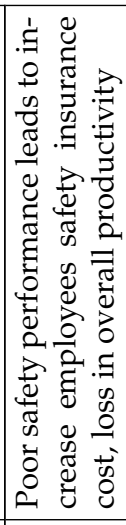 \\
\hline & 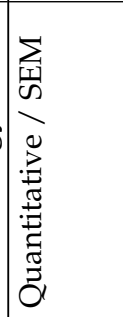 & 恣 & 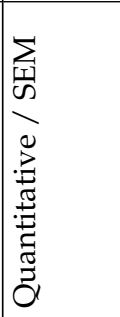 & 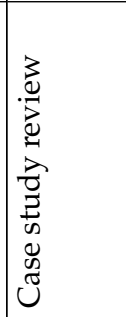 & 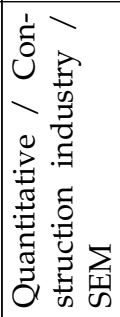 & 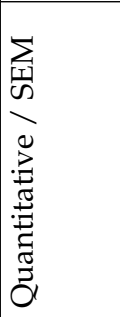 & 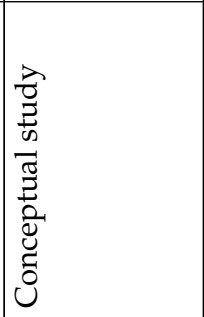 & 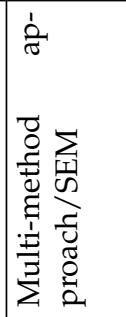 & 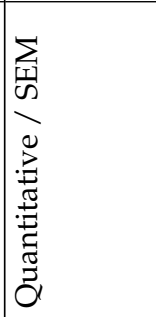 & 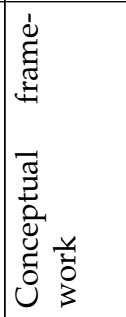 \\
\hline 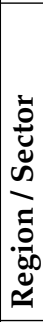 & 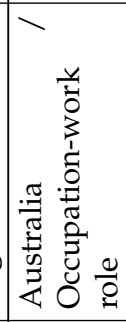 & 光 & 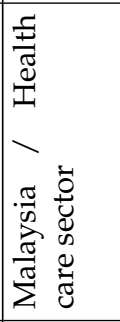 & 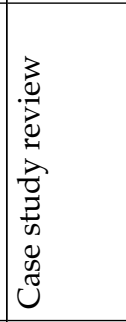 & 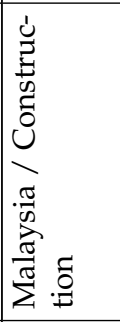 & 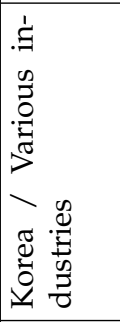 & 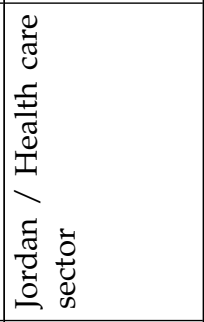 & 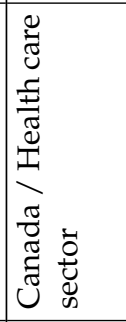 & 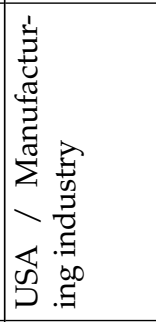 & 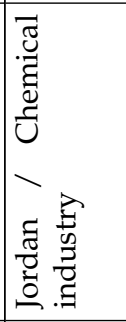 \\
\hline 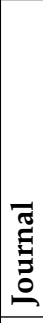 & 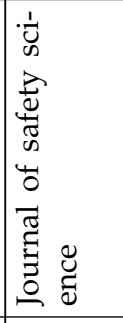 & 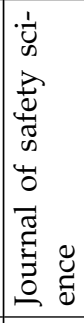 & 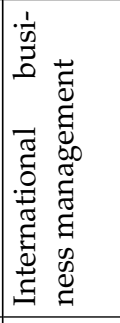 & 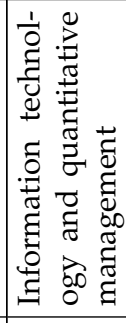 & 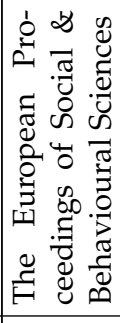 & 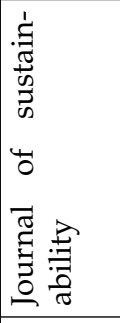 & 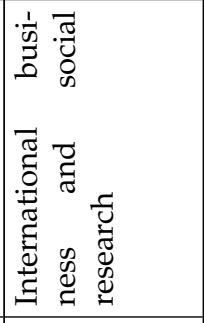 & 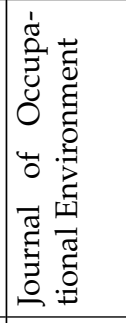 & 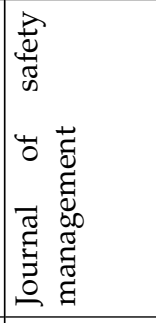 & 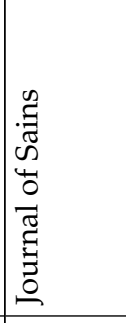 \\
\hline$\frac{0}{\frac{2}{2}}$ & 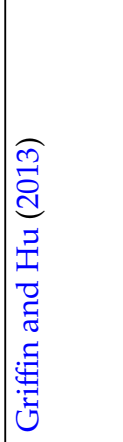 & 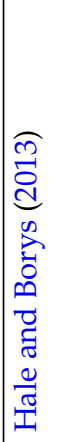 & 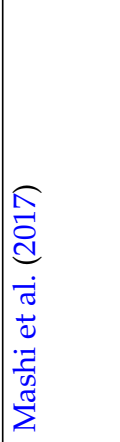 & 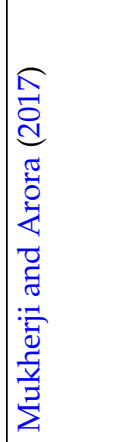 & 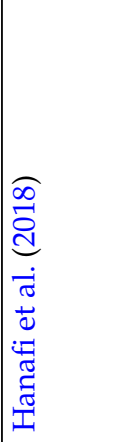 & 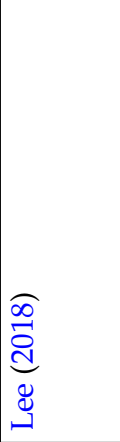 & 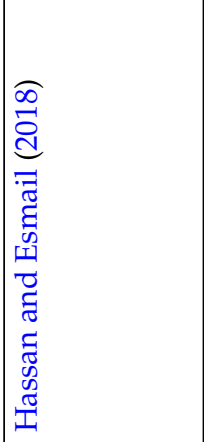 & 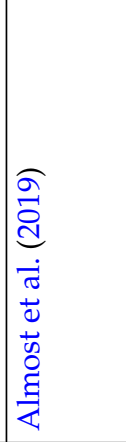 & 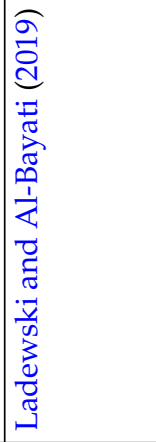 & 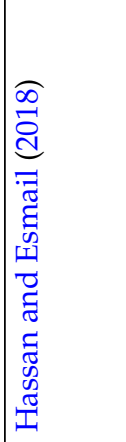 \\
\hline
\end{tabular}


Ajmal, Isha, \& Nordin

\begin{tabular}{|c|c|c|c|c|}
\hline & 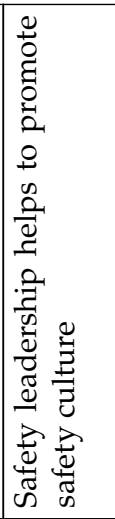 & 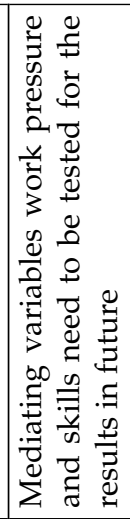 & 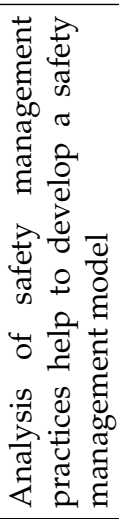 & 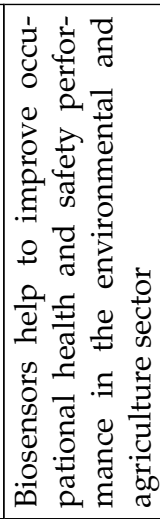 \\
\hline 20 & 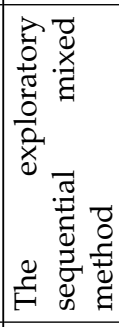 & 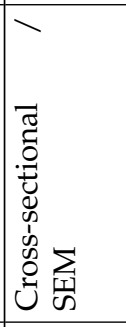 & 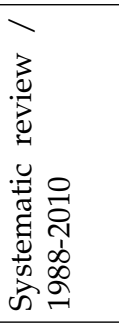 & \begin{tabular}{|l}
3 \\
$\stackrel{3}{0}$ \\
$\frac{0}{2}$ \\
$\simeq$
\end{tabular} \\
\hline 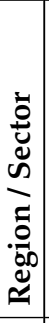 & 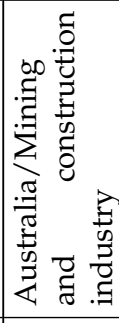 & 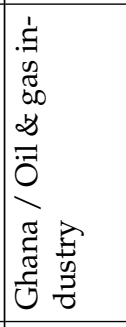 & 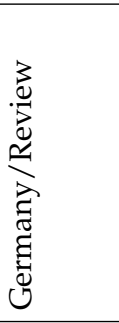 & 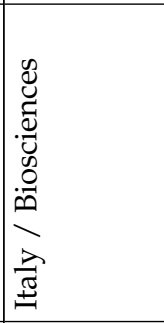 \\
\hline$\stackrel{\widetilde{\Xi}}{\Xi}$ & 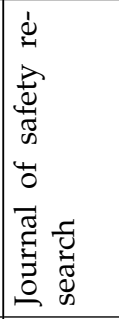 & 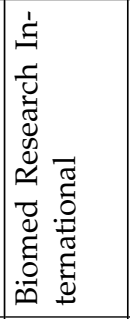 & 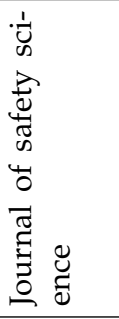 & 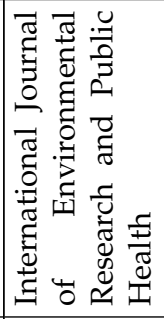 \\
\hline$\underbrace{E}$ & \begin{tabular}{|l}
$\tilde{\sigma}$ \\
$\tilde{U}$
\end{tabular} & 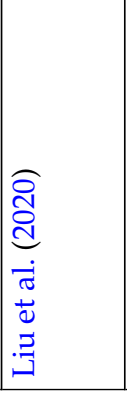 & 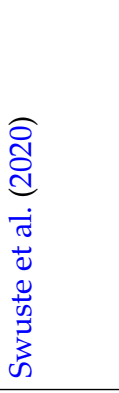 & 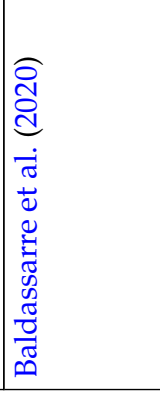 \\
\hline
\end{tabular}




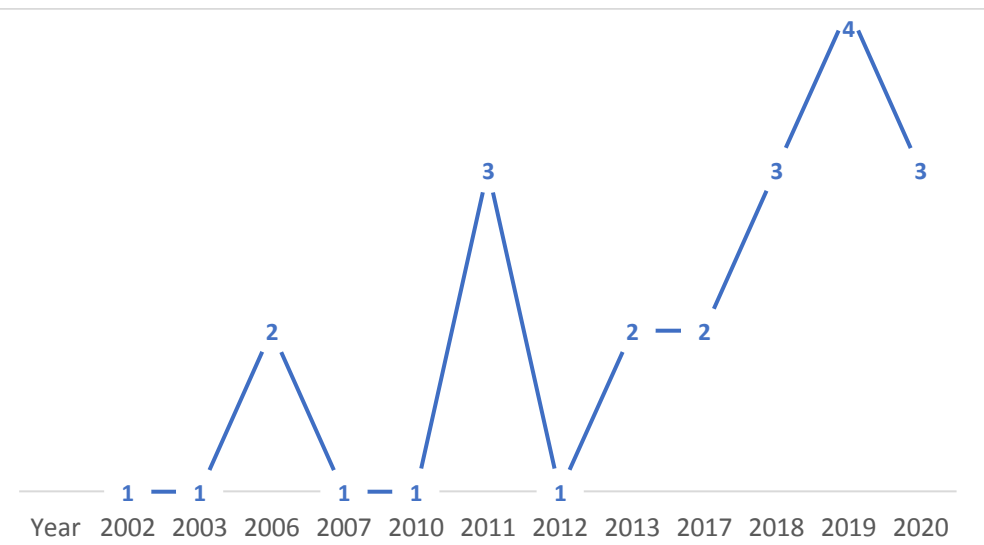

Figure 1: Year-wise Distribution of Publications on Safety Management Practices and Occupational Health and Safety Performance

In this study, quantitative discussed the impact of safety management practices on occupational health and safety management practices. Besides, most publications on safety management practices and occupational health and safety performance were published in $(2018,2019)$ and (2020-September) 3 research papers even though some fluctuation is showing the importance of safety management practices importance and occupational health and safety performance interest for the researchers in future. The current trend from (2019-2020), indicating that more research papers will appear on safety management practices and occupational health and safety performance. Interdisciplinary research on safety management practices and occupational health and safety performance papers have been published in various outlets. Among $(n=24)$ papers $(n=13)$ papers have been published in Scopus journals and $(n=11)$ have been published in ISI impact factor journals. The findings of these research papers also revealed that research on safety management practices and occupational health and performance has increasingly distributed over the range of safety management, health and safety, and social sciences journals.

\subsection{Research Context and Methodology}

The relationship between safety management practices and occupational health and safety performance was investigated in different industries and regions. The samples of 24 articles were found in 12 countries, in which Australia, UK, Malaysia, India, and the USA top ranking with three papers in each country. This is indicative that studies on safety management practices and occupational health and safety performance have gained attention wide geographically. The above (Figure.1) graph is showing the gradual improvement in research in the area of safety management practices and occupational health and safety performance in different sectors including construction, manufacturing, SMEs, and Oil and gas industry. There are two methodologies that researchers use for the data analysis quantitative and qualitative so, among $(n=24)$ quantitative approach was accounted $(n=14)$ used structural equation modeling techniques and $(n=5)$ multiple regression data analysis techniques, $(n=5)$ mixed-method approach was used. No case studies approach was found in selected papers for the systematic literature review. 4.3 The relationship between safety management practices and occupational health and 
safety performance According to the International Labor Organization (ILO) reports every 15 seconds due to work-related accidents and injuries a worker dies. The global gross domestic products $4 \%$ impede every year, probably due to 317 million accidents and injuries around the globe (Buwalda et al., 2003). In addition, every year, 2.3 million deaths occur related to occupational accidents and work-related injuries and 6300 employees per day. In developing countries where economic impede is growing upward is an alarming situation for high hazardous industries, e.g. oil and gas, manufacturing, construction (Lee, 2018). Safety Management practices play an important role in safety-critical organizations to manage safety and reduce the rate of work-related injuries (Vredenburgh, 2002). However, safety management practices are the functions to play roles in organizations to remain safe (Ladewski and Al-Bayati, 2019). It is the sub-system of overall organizational safety management and is performed via various safety management practices, including safety training, management commitment to safety, employee safety participation (Kirwan, 1998). According (Fernández-Muñiz et al., 2007; Lee, 2018; Vinodkumar and Bhasi, 2010; Vredenburgh, 2002), high-hazardous organizations focus on safety management practices to enhance occupational health and safety performance. Hanafi et al. (2018) argued that workplace health and safety performance indirectly influence the safety management budget of the organization. However, safety management practices include strategies, policies and rules that are implemented by the organization including employees safety training, employees participation for safety, safety compliance and management commitment for the workplace safety (Hanafi et al., 2018; Jacobs et al., 2015).

Our review shows that the developmental and multifaceted nature of safety management practices is not surprised with a broad range of practices including employee safety training, management safety commitment, safety rules and procedures, employees safety participation, and safety knowledge sharing. The review shows that limited studies have been covered most frequently safety management practices, e.g. management commitment to safety and safety participation rewards (Vinodkumar and Bhasi, 2010). The analysis of this study shows that most papers focused on management safety commitment to reduce the chances of occupational injuries and accidents rate $(n=9)$. However, employee safety training has also gained attention to equipping employees with safety skills and knowledge (Mazzetti et al., 2020) and $(\mathrm{n}=3)$ papers more focused on employees safety training. The instruments used in these studies were mostly adopted, and our review also found that $(\mathrm{n}=4)$ used different theories for example (Baldassarre et al., 2020; Lee, 2018; Liu et al., 2020). The findings revealed that the number of mediators and moderators have been used to improve the occupational health and safety performance in most risk hazardous organizations. These mediators and moderators were including safety motivation, safety participation, safety behaviour and safety knowledge. In review studies on safety management practices and occupational health and safety performance have received the most attention (Almost et al., 2019; Baldassarre et al., 2020; Hanafi et al., 2018; Mashi et al., 2017). The elicited findings from the 24 papers on safety management practices and occupational health and safety performance showing the relationship in outline a model (Figure.2).

\section{Discussion and Recommendation for Future Research}

This research aimed to extract and synthesize the literature on safety management practices and occupational health and safety performance. In our review, we have observed that research on safety management practices and occupational health and safety performance has gained attention since last two decades and a plethora of publications show that safety management 


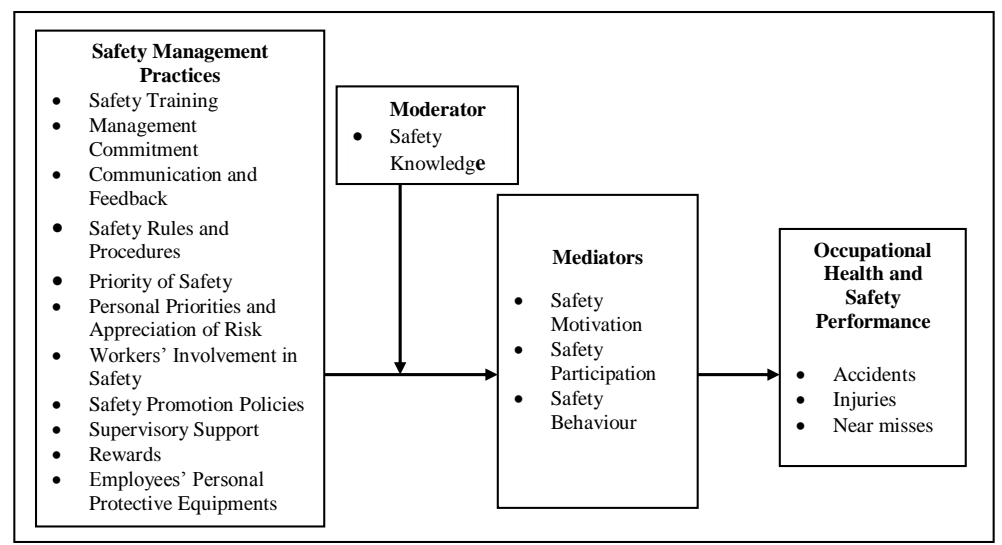

Figure 2: Model of the Relationship between Safety Management Practices and Occupational Health and Safety Performance

practices have been used in a different context and organizational perspectives including construction, manufacturing, and SMEs. Hence, the previous studies show that safety management practices are important to improve occupational health and safety performance (Liu et al., 2020; Vinodkumar and Bhasi, 2010; Vredenburgh, 2002; ?). However, this study offers new avenues for future research into the area of safety management practices and occupational health and safety performance.

\subsection{Research Design Advancement}

The analysis of research studies related to safety management practices and occupational health and safety performance shows that in many contexts quantitative approach has been applied. Therefore, to build more useful theories and better insights, more quantitative and qualitative studies are encouraged. We also recommend using the mixed method approach to understand the relationship between safety management practices and occupational health and safety performance. In previous studies, mostly structural equation modeling (SEM) technique has been applied to analyze the data. Still, in the qualitative study, NVivo software can use to analyze the qualitative data of the study. In designing a mixed-method approach, research might pair interviews, surveys to identify the most important safety management practices to analyze the relationship with occupational health and safety performance. This study can be about employees working in high hazardous workplaces in organizational departments, including manufacturing and production.

\subsection{Implications for Research and Practice}

This study is significant in several ways for practical and theoretical contribution to the existing body of knowledge. From the theoretical perspectives, this study extends the existing literature on safety management practices and occupational health and safety performance. In comparison, past review posits that safety management practices contribute significantly to reduce the accident rate, near misses, and injuries. The current study suggests positive relation- 
ships between safety management practices and occupational health and safety performance (Vinodkumar and Bhasi, 2010). Additionally, our review expanded previous literature and provided a detailed conceptual model on safety management practices. Occupational health and safety performance with mediating and moderating variables, as well as this study suggests alternative research avenues for future studies. This review in practical perspective provides overall existing picture knowledge of safety management practices and occupational health and safety performance that will be fruitful for experts to understand the importance of the development of strategies. For example, employees safety training helps to improve employees safety skills and knowledge to perform job-related duties safely. Moreover, management commitment to safety has been found a very important practice to maintain and improve occupational health and safety performance. Besides, both safety managers and the production and manufacturing department should collaborate to foster occupational health and safety performance with safety management practices. Safety managers should build teams to develop a culture for safetyrelated knowledge sharing and employees safety participation. The management of organizations should update safety rules and procedures to reduce the hazardous risks and chances of accidents and injuries. The department of occupational health and safety should ensure the safety compliance practices that employees are following to maintain safety performance.

\subsection{Conclusion}

This paper aimed to review the existing literature comprehensively on safety management practices and occupational health and safety performance to recommend for future research directions. The key findings of the research study have emerged that safety management practices have become important in the last two decades and several interesting studies have been conducted in numerous industries. Notably, safety performance is one of the major compelling forces to adopt and implement safety management practices effectively, and most studies have been investigated quantitatively in many countries and sectors. Second, management commitment and employees safety training has been identified as most important to maintain occupational health and safety performance along with safety knowledge sharing. The review also revealed that the number of mediating variables and moderating variables play an important role to build the relationship between safety management practices and occupational health and safety performance. Based on findings and literature review investigation, we provided a nuanced conceptual model showing the relationship between safety management practices and occupational health and safety performance. We also recommended the directions for future research on occupational health and safety performance, and one protentional limitation is all the papers included in this study were written in the English language. In future research studies can include studies from other languages apart from English to know the contradiction related to safety management practices and occupational health and safety performance.

\section{References}

Acar, A. Z. and Acar, P. (2014). Organizational culture types and their effects on organizational performance in turkish hospitals. EMAJ: Emerging Markets Journal, 3(3):18-31.

Ajmal, M., Isha, A. S. N., Nordin, S. M., Kanwal, N., Al-Mekhlafi, A.-B. A., and Naji, G. M. A. (2020).
A conceptual framework for the determinants of organizational agility: Does safety commitment matters? Solid State Technology, 63(6):4112-4119.

Ajmal, M., Isha, A. S. N., Nordin, S. M., Sabir, A. A., Munir, A., Al-Mekhlafi, A.-B. A., and Naji, G. M. A. (2021). Safety management paradigms: Covid-19 employee well-being impact on occupational health and safety performance. Journal 
of Hunan University Natural Sciences, 48(3).

Alingh, C. W., Strating, M. M., van Wijngaarden, J. D., Paauwe, J., and Huijsman, R. (2018). The concom safety management scale: developing and testing a measurement instrument for control-based and commitment-based safety management approaches in hospitals. BMJ quality $\mathcal{E}$ safety, 27(10):807-817.

Almost, J., Tett, L. C., VanDenKerkhof, E., Paré, G., Strahlendorf, P., Noonan, J., Hayes, T., Holden, J., e Silva, V. S., Rochon, A., et al. (2019). Leading indicators in occupational health and safety management systems in healthcare: A quasiexperimental longitudinal study. Journal of occupational and environmental medicine, 61(12):e486e496.

Alphs, L. D. and Anand, R. (1999). Clozapine: the commitment to patient safety. Journal of Clinical Psychiatry, 60(12):39-42.

Amponsah-Tawaih, K. and Adu, M. A. (2016). Work pressure and safety behaviors among health workers in ghana: the moderating role of management commitment to safety. Safety and health at work, 7(4):340-346.

Apisarnthanarak, A., Bangsong, R., Saelao, A., Pothirat, T., Rutjanawech, S., Khawcharoenporn, T., and Mundy, L. M. (2014). Assessment of the 2007 thai commitment to the global patient safety campaign. American journal of infection control, 42(6):690-691.

Arteta, B. M. and Giachetti, R. E. (2004). A measure of agility as the complexity of the enterprise system. Robotics and computer-integrated manufacturing, 20(6):495-503.

Asibey, M. O., Amponsah, O., and Yeboah, V. (2019). Solid waste management in informal urban neighbourhoods. occupational safety and health practices among tricycle operators in $\mathrm{ku}-$ masi, ghana. International journal of environmental health research, 29(6):702-717.

Autenrieth, D. A., Brazile, W. J., Sandfort, D. R., Douphrate, D. I., Román-Muñiz, I. N., and Reynolds, S. J. (2016). The associations between occupational health and safety management system programming level and prior injury and illness rates in the us dairy industry. Safety science, 84:108-116.

Aziz, B. (1993). The effective management of occupational health and safety: the requirement for accreditation for quality in the health services. International journal of health care quality assurance.

Baldassarre, A., Mucci, N., Lecca, L. I., Tomasini, E., Parcias-do Rosario, M. J., Pereira, C. T., Arcangeli, G., and Oliveira, P. A. B. (2020). Biosensors in occupational safety and health management: A narrative review. International journal of environmental research and public health, 17(7):2461.

Bhatnagar, J. (2007). Talent management strategy of employee engagement in indian ites employees: key to retention. Employee relations.

Borowski, D., Sieroszewski, P., Czuba, B., Jaczynska, R., Anna, K., Kwiatkowski, S., Wiechec, M., Nocun, A., Kaczmarek, P., Cnota, W., et al. (2020). Polish society of gynecology and obstetrics statement on safety measures and performance of ultrasound examinations in obstetrics and gynecology during the sars-cov-2 pandemic. Ginekologia polska, 91(4):231-234.

Buwalda, J., Schouwenburg, P., Blank, L., Merks, J., Copper, M., Strackee, S., Voute, P., and Caron, H. (2003). A novel local treatment strategy for advanced stage head and neck rhabdomyosarcomas in children: results of the amore protocol. European journal of cancer, 39(11):1594-1602.

Chandrasekar, K. (2011). Workplace environment and its impact on organisational performance in public sector organisations. International journal of enterprise computing and business systems, 1(1):1-19.

Christian, M. S., Bradley, J. C., Wallace, J. C., and Burke, M. J. (2009). Workplace safety: a metaanalysis of the roles of person and situation factors. Journal of applied psychology, 94(5):1103.

Clarke, S. (2006). The relationship between safety climate and safety performance: a meta-analytic review. Journal of occupational health psychology, 11(4):315. 
Classen, D. C., Holmgren, A. J., Newmark, L. P., Seger, D., Danforth, M., Bates, D. W., et al. (2020). National trends in the safety performance of electronic health record systems from 2009 to 2018. JAMA network open, 3(5):e205547-e205547.

Cousins, F., Reid, P., and Tait, E. (2019). Bridging the divide: Reflections on university-industry collaboration for the development of the graduate certificate in petroleum data management. Journal of documentation.

DeVaul, R. (2013). Survey says... renewed commitment to safety needed. Occupational health $\mathcal{E}$ safety (Waco, Tex.), 82(6):12-16.

Dov, Z. (2008). Safety climate and beyond: A multilevel multi-climate framework. Safety science, 46(3):376-387.

Dyjack, D., Levine, S., Holtshouser, J., and Schork, M. (1998). Comparison of aiha iso 9001-based occupational health and safety management system guidance document with a manufacturer's occupational health and safety assessment instrument. American Industrial Hygiene Association Journal, 59(6):419-429.

Eklof, M. and Ahlborg Jr, G. (2016). Improving communication among healthcare workers: a controlled study. Journal of Workplace Learning.

Ellinger, A. E., Ellinger, A. D., et al. (2014). Examining the influence of strategic profit emphases on employee engagement and service climate. Journal of Workplace Learning.

Farndale, E. and Murrer, I. (2015). Job resources and employee engagement: A cross-national study. Journal of Managerial Psychology.

Feng, X., Acord, L., Cheng, Y.-J., Zeng, J., and Song, J. P. (2011). The relationship between management safety commitment and patient safety culture. International nursing review, 58(2):249-254.

Fernández-Muñiz, B., Montes-Peon, J. M., and Vazquez-Ordas, C. J. (2007). Safety management system: Development and validation of a multidimensional scale. Journal of Loss Prevention in the process Industries, 20(1):52-68.

Ferreira, P. and de Oliveira, E. R. (2014). Does corporate social responsibility impact on employee engagement? Journal of Workplace Learning.
Frangieh, C. G. and Yaacoub, H. K. (2017). A systematic literature review of responsible leadership: Challenges, outcomes and practices. Journal of Global Responsibility.

Fruhen, L. S., Griffin, M. A., and Andrei, D. M. (2019). Erratum to" what does safety commitment mean to leaders? a multi-method investigation" [journal of safety research, 70 (2019) 169180]. Journal of safety research, 70:R1-R1.

Gao, Y., Fan, Y., Wang, J., Li, X., and Pei, J. (2019). The mediating role of safety management practices in process safety culture in the chinese oil industry. Journal of Loss Prevention in the Process Industries, 57:223-230.

Ghosh, P., Rai, A., and Sinha, A. (2014). Organizational justice and employee engagement: Exploring the linkage in public sector banks in india. Personnel Review.

Gilkey, D. P., Keefe, T. J., Hautaluoma, J. E., Bigelow, P. L., Herron, R. E., and Stanley, S. A. (2003). Management commitment to safety and health in residential construction: Homesafe spending trends 1991-1999. Work, 20(1):35-44.

Glendon, A. I. and Litherland, D. K. (2001). Safety climate factors, group differences and safety behaviour in road construction. Safety science, 39(3):157-188.

Griffin, M. A. and Hu, X. (2013). How leaders differentially motivate safety compliance and safety participation: The role of monitoring, inspiring, and learning. Safety science, 60:196-202.

Grill, M., Pousette, A., Nielsen, K., Grytnes, R., and Törner, M. (2017). Safety leadership at construction sites: the importance of rule-oriented and participative leadership. Scandinavian journal of work, environment $\mathcal{E}$ health, pages 375-384.

Hale, A. and Borys, D. (2013). Working to rule, or working safely? part 1: A state of the art review. Safety science, 55:207-221.

Hanafi, F. H. M., Rezania, S., Taib, S. M., Din, M. F. M., Yamauchi, M., Sakamoto, M., Hara, H., Park, J., and Ebrahimi, S. S. (2018). Environmentally sustainable applications of agro-based spent mushroom substrate (sms): an overview. Journal of Material Cycles and Waste Management, 20(3):1383-1396. 
Harris, T. B., Chung, W., Frye, C. L., and Chiaburu, D. S. (2014). Satisfaction guaranteed? enhanced impact of trainer competence for autonomous trainees. Industrial and commercial training.

Haslinda, A., Saharudin, S., Roslan, N. H., Mohamed, R., et al. (2016). Safety training, company policy and communication for effective accident management. Int. J. Acad. Res. Bus. Soc. Sci, 6(9):141.

Hassan, A. M. A. Z. and Esmail, J. M. (2018). A conceptual framework for upgrading safety performance by influence safety training, management commitment to safety and work environment: Jordanian hospitals. International Journal of Business and Social Research, 8(07):25-35.

Heaven, C., Clegg, J., and Maguire, P. (2006). Transfer of communication skills training from workshop to workplace: the impact of clinical supervision. Patient education and counseling, 60(3):313-325.

Hoffman, J. J. (1998). Evaluating international ethical climates: A goal programming model. Journal of Business ethics, 17(16):1861-1869.

Hofmann, D. A. and Morgeson, F. P. (1999). Safetyrelated behavior as a social exchange: The role of perceived organizational support and leadermember exchange. Journal of applied psychology, 84(2):286.

Hong, K. T., Surienty, L., and Hung, D. K. M. (2011). Safety management practices and safety behaviour: A preliminary investigation in malaysian small and medium enterprises in northern corridor economic region (ncer). Journal Occupational Safety $\mathcal{E}$ Health, 8:1-11.

$\mathrm{Hu}$, X., Casey, T., and Griffin, M. (2020). You can have your cake and eat it too: Embracing paradox of safety as source of progress in safety science. Safety Science, 130:104824.

Huang, Y.-H., Lee, J., McFadden, A. C., Murphy, L. A., Robertson, M. M., Cheung, J. H., and Zohar, D. (2016). Beyond safety outcomes: An investigation of the impact of safety climate on job satisfaction, employee engagement and turnover using social exchange theory as the theoretical framework. Applied ergonomics, 55:248257.
Inkinen, H. (2016). Review of empirical research on knowledge management practices and firm performance. Journal of knowledge management.

Jacobs, A., Hernández, J. C., and Buckley, C. (2015). Behind deadly tianjin blast, shortcuts and lax rules. New York Times.

Kim, H. and Scott, C. (2019). Change communication and the use of anonymous social media at work: Implications for employee engagement. Corporate Communications: An International Journal.

Kim, J. and De Dear, R. (2013). Workspace satisfaction: The privacy-communication trade-off in open-plan offices. Journal of Environmental Psychology, 36:18-26.

Kirwan, B. (1998). Human error identification techniques for risk assessment of high risk systemspart 1: review and evaluation of techniques. Applied ergonomics, 29(3):157-177.

Ladewski, B. J. and Al-Bayati, A. J. (2019). Quality and safety management practices: The theory of quality management approach. Journal of Safety Research, 69:193-200.

Lee, D. (2018). The effect of safety management and sustainable activities on sustainable performance: Focusing on suppliers. Sustainability, 10(12):4796.

Lestari, F., Bowolaksono, A., Yuniautami, S., Wulandari, T. R., and Andani, S. (2019). Evaluation of the implementation of occupational health, safety, and environment management systems in higher education laboratories. Journal of chemical health $\mathcal{E}$ safety, 26(4-5):14-19.

Liu, S., Nkrumah, E. N. K., Akoto, L. S., Gyabeng, E., and Nkrumah, E. (2020). The state of occupational health and safety management frameworks (ohsmf) and occupational injuries and accidents in the ghanaian oil and gas industry: assessing the mediating role of safety knowledge. BioMed research international, 2020.

Lubbe, S., Klopper, R., and Rugbeer, H. (2007). The matrix method of literature review. 
Mashi, M. S., Subramaniam, C., and Johari, J. (2017). The effect of management commitment, safety rules and procedure and safety promotion policies on nurses safety performance: The moderating role of consideration of future safety consequences. International Business Management, 11(2):478-489.

Mazzetti, G., Valente, E., Guglielmi, D., and Vignoli, M. (2020). Safety doesnt happen by accident: A longitudinal investigation on the antecedents of safety behavior. International journal of environmental research and public health, 17(12):4332.

Mearns, K., Whitaker, S. M., and Flin, R. (2003). Safety climate, safety management practice and safety performance in offshore environments. Safety science, 41(8):641-680.

Mehdibeigi, N., Yaghoubi, N., Dehghani, M., and Yaghoubi, E. (2018). Explaining the mediator role of organizational trust in the effect of managers' linguistic justice on staff's conflict management strategies at chabahar maritime and marine university. Journal of Research on Management of Teaching in Marine Sciences, 5(3):1-12.

Miller, J. (2017). Discrete time hazard modeling of large motor carriers' longitudinal safety performance. Transportation journal, 56(2):107-139.

Mitchell, R., Friswell, R., and Mooren, L. (2012). Initial development of a practical safety audit tool to assess fleet safety management practices. Accident Analysis \& Prevention, 47:102-118.

Mukherji, S. and Arora, N. (2017). Digital communication: easing operational outcomes in the workplace. Procedia computer science, 122:10841091.

Neal, A., Griffin, M. A., and Hart, P. M. (2000). The impact of organizational climate on safety climate and individual behavior. Safety science, 34(1-3):99-109.

Newnam, S. and Goode, N. (2019). Communication in the workplace: Defining the conversations of supervisors. Journal of safety research, 70:19-23.

O'Conaill, B. and Frohlich, D. (1995). Timespace in the workplace: Dealing with interruptions. In
Conference companion on Human factors in computing systems, pages $262-263$.

Onubi, H. O., Yusof, N., and Hassan, A. S. (2019). Adopting green construction practices: health and safety implications. Journal of Engineering, Design and Technology.

Pinion, C., Brewer, S., Douphrate, D., Whitehead, L., DelliFraine, J., Taylor, W. C., and Klyza, J. (2017). The impact of job control on employee perception of management commitment to safety. Safety science, 93:70-75.

Potdar, B., Guthrie, J., Gnoth, J., and Garry, T. (2018). Yours ethically: The role of corporate social responsibility and employee engagement in shoplifting prevention. International Journal of Retail \& Distribution Management.

Pruden, C. and Wadhwa, R. (2021). Medical simulation center director as a system improvement leader. StatPearls [Internet].

Reason, J., Parker, D., and Lawton, R. (1998). Organizational controls and safety: The varieties of rule-related behaviour. Journal of occupational and organizational psychology, 71(4):289-304.

Ros, A. and Gustafson, P. (2015). Patient safety require rules and procedures that are both followed and disregarded. Lakartidningen, 112.

Swuste, P., van Gulijk, C., Groeneweg, J., Guldenmund, F., Zwaard, W., and Lemkowitz, S. (2020). Occupational safety and safety management between 1988 and 2010: Review of safety literature in english and dutch language scientific literature. Safety science, 121:303-318.

Teoh, J. Y.-C., Cho, C.-L., Wei, Y., Isotani, S., Tiong, H.-Y., Ong, T.-A., Kijvikai, K., Chu, P. S.-K., Chan, E. S.-Y., Ng, C.-F., et al. (2020). Surgical training for anatomical endoscopic enucleation of the prostate. Andrologia, 52(8):e13708.

Thomé, A. M. T., Scavarda, L. F., and Scavarda, A. J. (2016). Conducting systematic literature review in operations management. Production Planning $\mathcal{E}$ Control, 27(5):408-420.

Townsend, P. and Gebhardt, J. (2006). The customer is always right: complete quality is inevitable for those who demand it. Industrial engineer, 38(5):41-46. 
Vecchio-Sadus, A. M. (2007). Enhancing safety culture through effective communication. Safety Science Monitor, 11(3):1-10.

Viitanen, T. and Siljander, A. (2021). A review of aeronautical fatigue investigations in finland april 2019-april 2021. In International Committee on Aeronautical Fatigue andStructural Integrity (ICAF) webinar: Online. VTT Technical Research Centre of Finland.

Vinodkumar, M. and Bhasi, M. (2010). Safety management practices and safety behaviour: Assessing the mediating role of safety knowledge and motivation. Accident Analysis E Prevention, 42(6):2082-2093.

Vredenburgh, A. G. (2002). Organizational safety: which management practices are most effective in reducing employee injury rates? Journal of safety Research, 33(2):259-276.

Whittaker, S., Frohlich, D., and Daly-Jones, O. (1994). Informal workplace communication: What is it like and how might we support it? In Proceedings of the SIGCHI conference on Human factors in computing systems, pages 131-137.

Zimolong, B. M. and Elke, G. (2006). Occupational health and safety management.

Zohar, D. (2000). A group-level model of safety climate: testing the effect of group climate on microaccidents in manufacturing jobs. Journal of applied psychology, 85(4):587.

Zohar, D. (2010). Thirty years of safety climate research: Reflections and future directions. Accident Analysis E Prevention, 42(5):1517-1522. 